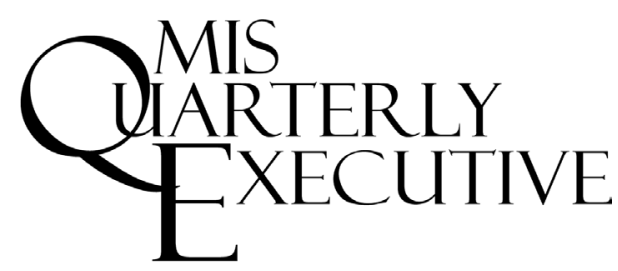

\title{
How Big Old Companies Navigate Digital Transformation
}

New digital technologies present both game-changing opportunities for-and existential threats to-companies whose success was built in the pre-digital economy. This article describes our findings from a study of 25 companies that were embarking on digital transformation journeys. We identified two digital strategies-customer engagement and digitized solutions - that provide direction for a digital transformation. Two technology-enabled assets are essential for executing those strategies: an operational backbone and a digital services platform. We describe how a big old company can combine these elements to navigate its digital transformation. ${ }^{1,2}$

Ina M. Sebastian

MIT Sloan Center for Information Systems Research (U.S.)

Jeanne W. Ross

MIT Sloan Center for Information Systems Research (U.S.)

Cynthia Beath

University of Texas at Austin (U.S.)
Martin Mocker

MIT Sloan Center for Information Systems Research (U.S.) and Reutlingen University

(Germany)

Kate G. Moloney

MIT Sloan Center for Information Systems

Research (U.S.)

Nils 0. Fonstad

MIT Sloan Center for Information Systems

Research (U.S.)

\section{Elements of Successful Digital Transformation}

New digital technologies, particularly what we refer to as SMACIT $^{3}$ (social, mobile, analytics, cloud and Internet of things [IoT]) technologies, present both game-changing opportunities and existential threats to big old companies. GE's "industrial internet" and Philips' digital platform for personalized healthcare information represent bets made by big old companies attempting to cash

1 Janis Gogan is the accepting senior editor for this article.

2 This research was previously reported in the Proceedings of the Thirty Seventh International Conference on Information Systems, Dublin, Ireland, December 2016. We thank the Track Chairs, Associate Editor and Reviewers of the Practice Track for their feedback and suggestions on our original submission.

3 This acronym is pronounced "smack it"-as in, score a digital strategy home run when you SMACIT out of the baseball park. There are more digital technologies than implied by this acronym, including artificial intelligence, blockchain, robotics and virtual reality. SMACIT is intended as shorthand for the entire set of powerful, readily accessible digital technologies. 
in on opportunities offered by digital technologies. ${ }^{4}$ LEGO is developing an engagement platform to supplement its enterprise systems with the ability to interact with customers and innovate rapidly. ${ }^{5}$ These big old companies are rethinking how they will compete in the digital economy, and they are investing in new technologies and new capabilities to reposition themselves as digital leaders.

In recent years, "born digital" pioneers (such as Amazon, Facebook and Google) have grown into powerful behemoths, while companies that had long dominated their industries found their traditional value propositions under threat. Most leaders of big old companies believe their companies can retain leadership positions by taking advantage of both their existing strengths and the capabilities offered by digital technologies. But what must they do to succeed? That is the question we set out to answer in a study of 25 large, successful companies initiating digital transformations. Most of these companies were "big" (with a mean size of 82,297 employees), and most were "old" (with a mean age of 104 years.) Our research method and sample are described in the Appendix.

Most big old companies' digital transformations are at an early stage - in most industries, the vast majority of established companies' revenues still come from traditional products and services. ${ }^{6}$ Thus, research on successful digital transformation is currently limited to identifying trends that signal improved capabilities to apply SMACIT and related technologies, and to the growing accessibility of electronic data to enrich products, services and customer relationships.

Our study revealed three essential elements for a successful digital transformation:

1. A digital strategy that defines a SMACITinspired value proposition

2. An operational backbone that facilitates operational excellence

4 For more information about these companies' digital innovations and their leaders' expectations, see https://www.ge.com/digital/industrial-internet and http://www.usa.philips.com/healthcare/innovation/ about-health-suite.

5 El Sawy, O. A., Kraemmergaard, P., Amsinck, H. and Vinther, A. L. "How LEGO Built the Foundation and Enterprise Capabilities for Digital Leadership," MIS Quarterly Executive (15:2), June 2016, pp. 143-166.

6 The annual reports of successful, well-established companies like BNY Mellon, Kaiser Permanente, Aetna, GE, Schneider Electric, Philips and the Schindler Group highlight their continued dependence on traditional sources of revenue even as they make significant investments in digital initiatives.
3. A digital services platform that enables rapid innovation and responsiveness to new market opportunities.

In this article, we explain how these three elements position big old companies for success in the digital era. We describe the digital initiatives of several companies in our study and offer evidence that shows how these efforts will contribute to long-term digital success. ${ }^{7}$ We conclude with recommendations for leaders of companies that are ready to embark - or have already embarked - on their digital transformation journeys.

\section{Two Digital Strategies}

As leaders in big old companies recognize the opportunities created by new digital technologies to integrate their existing business capabilities with new capabilities made possible by SMACIT technologies, they are defining their companies' digital strategies. ${ }^{8}$ These are not merely technology strategies. Rather, they are business strategies that incorporate the opportunities that the digital economy presents. ${ }^{9}$ We define a digital strategy as: A business strategy, inspired by the capabilities of powerful, readily accessible technologies (like SMACIT), intent on delivering unique, integrated business capabilities in ways that are responsive to constantly changing market conditions. A digital strategy guides leaders' efforts to create new value propositions by combining their companies' existing capabilities with capabilities enabled by SMACIT and other digital technologies.

\footnotetext{
7 In this article, we reference initiatives at Kaiser Permanente, Schindler Group, LEGO Group, Schneider Electric, Ferrovial and USAA. The Appendix includes links to our published case studies and shorter vignettes for these and other companies included in our study.

8 For more on developing digital strategies, see Ross, J. W., Sebastian, I. M. and Beath, C. M. "How to Develop a Great Digital Strategy," MIT Sloan Management Review, November 8, 2016, available at http://sloanreview.mit.edu/article/how-to-develop-a-greatdigital-strategy/.

9 We distinguish digital strategies from more traditional IT strategies - a digital strategy being the company's high-level business strategy, while an IT strategy is set to enable a business strategy. This distinction is also made in Bharadwaj, A., El Sawy, O. A., Pavlou, P. A. and Venkatraman, A. "Digital Business Strategy: Towards a Next Generation of Insights," MIS Quarterly (37:2), June 2013, pp. 471482. IT strategies are thoroughly reviewed in Peppard, J. and Ward, J. "Beyond Strategic Information Systems: Towards an IS Capability," Journal of Strategic Information Systems (13:2), July 2004, pp. 167194. For a broad review of different types of technology-related strategies, see Chen, D. Q., Mocker, M., Preston, D. S. and Teubner, A. "Information Systems Strategy: Reconceptualization, Measurement, and Implications," MIS Quarterly (34:2), June 2010, pp. 233-259.
} 
We found that company leaders who recognize the opportunities presented by new digital technologies articulate one of two types of digital strategy: customer engagement or digitized solutions. In our sample of 25 companies, eight were pursuing a customer engagement strategy, and 13 were pursuing a digitized solutions strategy. The remaining four were experimenting with applications of digital technologies but had not yet formulated a clear digital strategy and thus had not embarked on a transformation journey.

\section{Customer Engagement Strategy}

Just as Amazon's introduction of customer recommendations and user-friendly online interactions created a passionate base of loyal customers, a company pursuing a customer engagement digital strategy seeks to build customer loyalty and trust by providing superior, innovative, personalized and integrated customer experiences. A customer engagement strategy typically aims to create a seamless, omnichannel experience that makes it easy for customers to order, inquire, pay and receive support in a consistent way from any channel at any time. Such a strategy relies on analytics applied to a growing repository of customer data, to better understand and anticipate varying customer demands. In addition, this type of digital strategy facilitates ongoing communications between a company and its customers and, where appropriate, with a larger community.

An example of a company pursuing a customer engagement strategy is Kaiser Permanente, a U.S. non-profit integrated healthcare organization. Healthcare in the United States is shifting from volume-based to value-based care, with a focus on increasing access while also cutting costs. Kaiser Permanente is attempting to reduce costs and improve individual patient health by facilitating both preventive and traditional care. This involves shifting from a hospital-centric view of healthcare to a patient-centric view. EVP and CIO Richard Daniels explains:

"We need to make it easy for people to get access to care anytime and anywhere, preferably from any device, so that they can reach us. They can have access to their care team, and we want to provide them [with] leading-edge technology, like video

\section{[consultation] with your doctor from your} smartphone."

Kaiser Permanente is capitalizing on opportunities created by SMACIT technologies in at least three ways:

1. Offering increased opportunities for patient interaction with care delivery teams by supplementing visits and calls with channels like video, text and email

2. Investing in data analytics to identify needs for-and most effective approaches topersonalized outreach, particularly when it encourages patient adherence to medical regimens

3. Leveraging social media to develop communities of patients who have similar interests and to create care circles that engage patients and their families with care providers.

Ten years ago Kaiser Permanente was criticized for inconsistent customer service. ${ }^{10}$ As it delivers on its customer engagement strategy, it is earning the healthcare industry's highest "net promoter" scores. ${ }^{11}$ Seventy percent of Kaiser Permanente's members are actively engaged online, and studies conducted by the company reveal that actively engaged members are healthier, adhere more to prescribed medications, are more satisfied and are twice as likely to stay with the organization. Like other big old companies pursuing customer engagement digital strategies, Kaiser Permanente is leveraging digital technology to build customer loyalty, which, in turn, is building competitive advantage.

\section{Digitized Solutions Strategy}

A digitized solutions strategy aims to reformulate a company's value proposition by integrating a combination of products, services and data. This type of digital strategy is driven by R\&D efforts

10 See Goldsmith, J. "An Interview with George Halvorson: The Kaiser Permanente Renaissance, and Health Reform's Unfinished Business," Health Affairs, September 30, 2014, available at http:// healthaffairs.org/blog/2014/09/30/an-interview-with-georgehalvorson-the-kaiser-permanente-renaissance-and-health-reformsunfinished-business/.

11 At many companies we studied, net promoter score (NPS) is the key metric used to track customer satisfaction. Information on Kaiser Permanente's 2016 NPS can be found in "Kaiser Permanente Again Ranks No. 1 in Customer Loyalty", Kaiser Permanente Feature Story, June 29, 2016, available at https://share.kaiserpermanente.org/ article/kaiser-permanente-ranks-no-1-customer-loyalty/ 
that seek to anticipate-rather than respond tocustomer needs. Just as Steve Jobs trusted his instincts (rather than customer input) to guide product innovation at Apple, a company pursuing a digitized solutions strategy tries to imagine what it could do for customers by combining existing competencies with the capabilities offered by digital technologies. An effective digitized solutions strategy invariably involves collecting and using additional data - often gathered through sensors. In many cases, digitized solutions may shift company revenues from the sale of products to recurring revenue from ongoing services. ${ }^{12}$ An example of such a shift is GE's expectation of subscription revenue from its asset performance management offering, delivered via its Predix platform-as-aservice (PaaS).

One company in our study that is pursuing a digitized solutions strategy is the Schindler Group, a global provider of elevators, escalators and related services. The elevator and escalator industry is highly competitive, which severely constrains profit margins. Schindler has set out to create digitized solutions with the aim of establishing a unique space in the industry. Its products move one billion people a day - all within buildings in urban areas. Management thought that Schindler's competency in moving people, combined with digital technologies, would position it to provide mobility solutions beyond buildings. Schindler has therefore embraced a strategy called "urban mobility solutions" for experimenting with a much wider range of products and services. The first innovation that went into production involved using its PORT technology ${ }^{13}$ and sensor equipped elevators to grant access to registered guests at a building and direct them to their hosts.

"When you have our PORT technology on your phone, the building will recognize you and know where you want to go, so you don't need your badge. If you're a visitor, we send you a message on your smartphone, and then you can flow into the building without signing

\footnotetext{
12 For more on how digital technologies are transforming companies and competition, see Porter, M. E. and Heppelmann, J. E. "How Smart, Connected Products are Transforming Companies," Harvard Business Review (93:10), October 2015, pp. 96-114; and Porter, M. E. and Heppelmann, J. E. "How Smart, Connected Products are Transforming Competition," Harvard Business Review (92:11), November 2014, pp. 64-88

13 For more information, see http://www.schindlerportna.com/
}

in at the reception desk." Michael Nilles, Chief Digital Officer, Schindler Group

As part of its digitized solutions strategy, Schindler applies analytics to enhanced sensor data to develop both predictive maintenance models and smart algorithms that optimize routes to any destination in buildings and assign elevators. Like other big old companies pursuing a digitized solutions strategy, Schindler is leveraging digital technologies to offer integrated products and services that distinguish it from competitors.

\section{Choosing a Digital Strategy}

A digital strategy is valuable only if it drives resource allocation and capital investments. Many business leaders are reluctant to commit to one digital strategy, in part because they believe that digital success involves both customer engagement and digitized solutions. But our research found that the best strategies guided both strategic choices and operational decisions, and that committing to one strategy paid off. Companies like Kaiser Permanente, LEGO and USAA (a U.S. financial services company) that were pursuing a customer engagement strategy achieved greater customer satisfaction and loyalty. Companies like Schindler and Schneider Electric that were pursuing a digitized solutions strategy gained new sources of revenue. The value of strategic focus is well established, but the more noteworthy finding from our study may be that success with the chosen strategy eventually also led to outcomes associated with the other strategy.

At USAA, for example, seamless channel integration not only generated member delight and loyalty (at USAA customers are referred to as members), but led to increased product integration. USAA's responsiveness to members' needs led it to change its website so that its financial products were listed according to a member's life events. This new arrangement was helpful, but it quickly became clear that members would find it even more helpful if those products were actually integrated. That led USAA to create integrated solutions like AutoCircle - a one-stop shop for buying, insuring and financing an automobile.

Similarly, Schindler's pursuit of digitized solutions meant the company had to engage with customers to convince them of the benefits of those solutions. This led Schindler to design customer engagement tools that communicate the status of 
Schindler's (and some partners') equipment to customers (usually facility managers).

In short, our study reveals that there is a natural synergy between the two digital strategies. Despite this synergy, however, our research suggests that it is essential to commit to one digital strategy or the other. Committing to one strategy helps leaders make tough choices related to resource allocation. Moreover, digital technologies present so many opportunities that, without clear investment criteria, leaders will find themselves reacting to immediate one-off opportunities rather than proactively designing their business for digital success. In particular, they will find it difficult-or even impossible - to develop and use two technologyenabled assets that our research found are essential for executing a company's digital strategy.

\section{Two Technology-enabled Assets are Essential to Executing a Digital Strategy}

The companies we studied found it easier to articulate a digital strategy than to execute it. In fact, all the companies we studied (and we specifically sought out proactive companies for this research) are still at early stages of their digital transformations. (Indeed, we cannot declare that any of the companies we studied have successfully completed a digital transformation.)

We observed enormous variation in companies' abilities to deliver new digital services, such as a seamless omnichannel customer experience or a well-integrated IoT-based service. To consistently deliver new digital services, our research revealed, a company needs two technology-enabled assets: an operational backbone and a digital services platform.

The operational backbone supports efficiency and operational excellence, while the digital services platform supports business agility and rapid innovation. Both the operational backbone and digital services platform depend on a base of technology, but what makes them powerful is the business capabilities that the technology enables. Our research on business transformation initiatives suggests that these capabilities are the critical enablers of digital business success.

\section{An Operational Backbone Enables Operational Excellence}

To compete in the digital economy, companies must, at a minimum, be able to flawlessly execute transactions and provide access to critical operational data. To accomplish this, they need a strong and scalable operational backbone (also referred to as a digitized process platform). ${ }^{14} \mathrm{We}$ define an operational backbone as the technology and business capabilities that ensure the efficiency, scalability, reliability, quality and predictability of core operations.

Companies have been building operational backbones since the late 1990s, when implementations of ERP and customer relationship management (CRM) systems targeted the benefits of standardized and integrated systems and processes. ${ }^{15}$ Each company's operational backbone is focused on its own unique strategic requirements, but the most common elements include:

- A "single source of truth" for critical data (e.g., customer, order and product data)

- Seamless and transparent transaction processing

- Standardized back office shared services.

Although many businesses have been building operational backbones for many years, only 15 companies in our sample had operational backbones that supported their digital strategies. The other 10 had managed to survive without wiring in

14 For more information on digitized process platforms, see Ross, J. W., Weill, P. and Robertson, D. Enterprise Architecture as Strategy: Creating a Foundation for Business Execution, Harvard Business Press, 2006.

15 For more on how standardization and integration of processes has paid off, see Bradley, R., Pratt, R., Byrd, T. A. and Simmons, L. "The Role of Enterprise Architecture in the Quest for IT Value," MIS Quarterly Executive (10:2), June 2011 pp. 19-27; Tamm, T., Seddon, P. B., Shanks, G., Reynolds, R. and Frampton, K. "How an Australian Retailer Enabled Business Transformation Through Enterprise Architecture," MIS Quarterly Executive (14:4), December 2015, pp. 181-193; and Venkatesh, V., Bala, H., Venkatraman, S. and Bates, J. "Enterprise Architecture Maturity: The Story of the Veterans Health Administration," MIS Quarterly Executive (6:2), June 2007, pp. 79-90. 
operational excellence. ${ }^{16}$ Without an operational backbone, however, they lacked seamless operations. As a result, they did not have the basic competencies needed to execute a digital strategy.

Companies with operational backbones were increasingly able to automate repetitive processes, thus enhancing speed and accuracy. Moreover, the reliability provided by the operational backbone allowed management to focus on strategic issues rather than fighting fires. LEGO and Kaiser Permanente offer examples of how powerful operational backbones give companies the operational excellence critical to executing their digital strategies.

LEGO's Operational Backbone. In 2004, LEGO (renowned for construction kits using the iconic LEGO brick) could not reliably and costeffectively deliver its products to retailers. Its supply chain problems were so severe at the time that LEGO was facing bankruptcy. ${ }^{17}$ Jørgen Vig Knudstorp, LEGO's CEO, recognized that fixing the supply chain was essential to business success:

"One of the things that dawned on me when $I$ arrived at the LEGO Group was that basically you have an allocation problem. You are producing 100,000 components every minute, 24 hours a day, 365 days a year. And you have to allocate them in optimal quantities at different sites, so that you can deliver a set of finished products at Walmart in Arkansas on Tuesday at 5:00 p.m. (and not 5:00 a.m.) in optimal order quantity, optimal transportation quantity, optimal manufacturing batches and so on."

LEGO addressed its crisis by leveraging an under-used ERP system to get its supply chain processes under control. That effort was sufficient to turn the company around, but leadership recognized that other processes were still creating costly

\footnotetext{
16 The fact that $60 \%$ of the companies in our sample have a value-adding operational backbone suggests that we were successful in recruiting technologically mature companies for our study. Our recent survey of 171 senior IT leaders found that only $28 \%$ of established companies have value-adding operational backbones. See Ross, J. W., Sebastian, I. M and Jha, L., and the Technology Advantage Practice of The Boston Consulting Group, Designing Digital Organizations-Summary of Survey Findings, MIT CISR Working Paper No. 415, February 2017, available at http://cisr.mit.edu/blog/ documents/2017/02/28/mit_cisrwp415_ddosurveyreport_rosssebastianbeathjhabcg.pdf/.

17 For details on LEGO's business turnaround, see Robertson, D. C. Brick by Brick, Crown Business Books, 2013.
}

inefficiencies. To address these problems, LEGO followed its supply chain management initiative with programs that standardized processes related to HR management, manufacturing and product lifecycle management. By 2012, these efforts had provided efficient, reliable core processes and transparent master data, and had improved customer satisfaction. With the operational backbone in place, management could now focus on defining and pursuing a digital strategy - one that focused on developing the builders of tomorrow.

\section{Kaiser Permanente's Operational}

Backbone. The operational backbone at Kaiser Permanente is built around the electronic health record (EHR). U.S. healthcare providers generate a great deal of data about patients, but as patients interact with multiple caregivers, the data relating to an individual tends to be poorly integrated. Poorly integrated systems and data lead to frustrated patients and clinicians, who must cope with incomplete information, delays in follow-up actions, inaccurate billing and even medical errors. By taking a disciplined approach to managing its EHR processes and patient data, Kaiser Permanente introduced an extraordinary level of operational excellence. In turn, operational excellence positions the company to pursue a digital strategy centered on enhanced collaboration between healthcare providers, patients and their families.

Challenges and Benefits of Operational Backbones. For big old companies, developing an operational backbone is a long, expensive and transformative journey. Our study revealed that even companies with powerful operational backbones need to continuously invest in improvements and extensions. Many leaders told us that their operational backbones provided a slew of operational and strategic benefits, including cost savings, reliability that generated profits and customer satisfaction, scalability following the launch of new products and markets, and the ability to integrate new acquisitions. These types of benefit have helped companies compete for many years. The new - and critically important-benefit of an operational backbone is that it also establishes a strong and stable foundation for introducing new digital products and features. It frees up management attention to pursue digital innovations and ensures that existing business capabilities can be integrated, as needed, with new digitally enabled capabilities. 
In our study, we also learned that while an operational backbone is necessary, it is not sufficient for successfully executing a digital strategy. A digital services platform is also needed.

\section{A Digital Services Platform Enables Rapid Innovation}

Because an operational backbone is designed for reliability and efficiency, it does not offer the speed and flexibility that companies need for rapid digital innovation. Thus, in addition to an operational backbone, companies also need a digital services platform, which we define as the technology and business capabilities that facilitate rapid development and implementation of digital innovations.

The architecture of a digital services platform must facilitate experimentation and provide reusable technology and digital services. Common characteristics of digital services platforms include:

- Digital components that enable a variety of technical and business services (e.g., biometric authentication, customer alerts)

- Platform as a service (PaaS) - a cloudbased hosting environment for storing and accessing loosely connected services

- Repositories for massive amounts of data, whether from public sources (e.g., from social media), purchased or derived from sensors

- Analytics engines for converting data into meaningful insights

- Connections to data and processes that reside in the company's operational backbone.

Recognizing that their operational backbones were not designed for rapid digital innovation, leaders in our study were beginning to design and build digital services platforms.

Kaiser Permanente's Digital Services Platform. Kaiser Permanente launched its "Generation 2 Platform" in June 2014. This platform supports technology components for developing clinical and operational services that can be assembled via a cloud-based self-service portal (21 services at the time of our study, with many more planned). As of 2016, the portal had delivered more than 1,000 systems - all within one day of a request. New systems enable Kaiser Permanente to create new opportunities for caregivers and patients to share data, consult, commiserate and learn. The Generation 2 platform, along with the IT services management model, has greatly improved Kaiser Permanente's capacity to produce digital innovations across clinical and operational departments.

"Our vision is really simple: it's to be as easy as Amazon. You can go to their website; you get recommendations, you know what you can order-you don't need training to use their website. You can click on how much it's going to cost, you can have a payment transaction, and then there's almost perfection in their logistics. Your package is tracked. You get alerts. It's all self-service, self-enabled." Mike Sutten, Senior Vice President and Chief Technology Officer, Kaiser Permanente

LEGO's Digital Services Platform. LEGO is building an "engagement platform" that supports experimentation and rapid introduction (and, as necessary, elimination) of functionality. The engagement platform will allow the company to continuously adapt its digital interface according to the preferences of individual customers, thus providing a personalized digital experience. For LEGO toys with digital capabilities, the platform will facilitate rapid software updates, so that even older kits will provide new experiences. Finally, the platform will provide an environment for working with digital partners on joint product development and for giving approved partners access to LEGO functionality.

Risks of Not Having a Digital Services Platform. A company that fails to design and build a well-defined digital services platform risks falling behind competitors that can rapidly act on digital opportunities. Developers can build digital functionality without a digital services platform but will likely generate a messy collection of individual services (i.e., APIs) that create new risks and hinder reuse. If instead they choose to build digital services on their operational backbone, development will be slow and expensive. Because operational backbones are built to ensure the integrity of transactions and master data, companies carefully manage releases for maintenance, upgrades and enhancements. However, when applied to digital services, this approach will severely limit innovation and, ultimately, competitiveness. 


\section{How Big Old Companies Accommodate Both an Operational Backbone and a Digital Services Platform}

Regardless of whether a big old company chooses a customer engagement or digitized solutions digital strategy, the most proactive companies in our research needed both an operational backbone and a digital services platform to deliver the efficiency, reliability, speed and agility that the competitive environment demands. Although these two assets support very different business capabilities, they are complementary. Digital services invariably have to link up with the operational backbone. Consider, for example, a company that collects IoT sensor data to help its customers manage the performance of their assets (such as GE's aircraft engines or Schneider Electric's connected energy management products). The digital service will rely on an operational backbone to provide customer data, invoicing and related transaction processing services. Similarly, operational backbones will be of limited value in a digital economy if they prevent companies from bringing innovative new services to market rapidly. Thus, big old companies that successfully transform will be those that can build and leverage both of these technology-enabled assets.

Given the history of technology, one might expect that an important distinction between an operational backbone and a digital services platform would be the technology on which each is built. However, we found that the important distinction is not technological. All 12 companies in our research that had implemented a digital services platform were relying on the cloud-most often a public cloud. And, although most of the 15 companies with an operational backbone had built it on mainframe technologies, these backbones increasingly ran, at least in part, on some form of cloud services.

For example, Ferrovial (a Spanish multinational that builds, manages and operates infrastructure projects and related services) found it could accelerate development of its operational backbone by using software as a service (SaaS) offerings. With this shift to the cloud, Ferrovial's 70,000 employees adopted new standardized HR and purchasing processes in six months. Similarly, Schneider Electric installed a cloud-based CRM system to facilitate cross selling in its diverse businesses. ${ }^{18}$ In 18 months, this system was adopted by 25,000 employees in 100-plus countries, and cross-selling increased by $20 \%$. We expect that many more companies will turn to SaaS to accelerate development of their operational backbones.

Thus, technology differences between operational backbones and digital services platforms are beginning to disappear. Nevertheless, we found that the different characteristics of these two assets give rise to two very different sets of management practices. Table 1 summarizes these contrasting requirements.

Companies have different objectives for the two technology-enabled assets. Reliability and efficiency are essential requirements for an operational backbone. Henrik Amsinck, LEGO's CIO, explains that his enterprise platform runs "beneath the human interaction" and is "the IT below all the business processes that run the LEGO Group end to end-all the software and hardware and wiring."

In contrast, Jørgen Vig Knudstorp, LEGO's CEO, highlighted that a digital services platform must facilitate rapid innovation:

"There are new spaces where software development is still at the edge and revolutionary - areas like consumer interaction and new products. What is the next upcoming disruptive gaming or consumerengaging technology that could really impact our business and our business model? That evolution is unlikely to take place anywhere near our [enterprise platform] development center."

Companies pursue these two different objectives by applying different architectural principles to the two technology-enabled assets. Roadmaps and traditional architecture reviews guide the development of an operational backbone's standardized business processes and controlled access to enterprise data. In contrast, a digital services platform relies on cross-functional development teams that apply user-centered design techniques to develop and assemble reusable plugand-play business and technology components.

In turn, the different goals and design principles lead to two different approaches to development.

18 See Karunakaran, A., Mooney, J. and Ross, J. W. Accelerating Global Digital Platform Deployment Using the Cloud: A Case Study of Schneider Electric's "Bridge Front Office" Program, MIT Sloan CISR Working Paper No. 399, January 2015. 
Table 1: Operational Backbones and Digital Services Platforms Require Fundamentally Different Management Practices

\begin{tabular}{|l|l|l|}
\hline $\begin{array}{l}\text { Management } \\
\text { Objective }\end{array}$ & Operational Backbone & Digital Services Platform \\
\hline $\begin{array}{l}\text { Architecture } \\
\text { Principles }\end{array}$ & $\begin{array}{l}\text { Standardized end-to-end business processes; } \\
\text { transparency into systems; data access }\end{array}$ & $\begin{array}{l}\text { Plug-and-play business and technology } \\
\text { components }\end{array}$ \\
\hline Data & Single source of truth for transactional data & $\begin{array}{l}\text { Massive repositories of sensor/social media/ } \\
\text { purchased data }\end{array}$ \\
\hline Key Processes & Roadmaps; architecture reviews & $\begin{array}{l}\text { Cross-functional development; user-centered } \\
\text { design }\end{array}$ \\
\hline Delivery Method & $\begin{array}{l}\text { Fast waterfall/regular software releases/SaaS } \\
\text { adoption }\end{array}$ & $\begin{array}{l}\text { Agile and DevOps; }{ }^{19} \text { use of MVP (minimum } \\
\text { viable product) concepts and constant } \\
\text { enhancements }\end{array}$ \\
\hline Funding & Major project/program investments & \begin{tabular}{l} 
Continuous funding by business owners \\
\hline
\end{tabular}
\end{tabular}

Most companies still use traditional development methods to build their operational backbonesalthough some interviewees mentioned that their traditional waterfall approach is evolving to a more collaborative, scaled-down "fast waterfall." Even using SaaS to build an operational backbone requires each new enterprise process to be deliberately developed and implemented.

In contrast, companies rely on agile development to deliver new services via their digital services platforms. Small cross-functional teams use iterative, agile methods to build and test new services with minimum viable products. Kaiser Permanente has implemented a DevOps model, which requires near-continuous deployment of new code to dramatically reduce cycle times for launching innovations. Amazon introduces new code onto its digital services platform every 11 seconds. ${ }^{20}$ It appears that, over time, DevOps capabilities will become a competitive necessity.

The objectives for digital services platforms are also causing traditional funding models to be disrupted. Traditional project funding approval is just too slow for continuous delivery of digital services-hence the rising popularity of pay-for-

19 DevOps, a compound of "development" and "operations," is a software development and delivery approach designed for high velocity. One company's overview of DevOps can be reviewed at https://aws.amazon.com/devops/what-is-devops/.

20 This number was reported in Bort, J. "Former EMC exec: Google's cloud efforts against Amazon are like 'a Microsoft phone' — too little too late," Business Insider, August 11, 2016, available at http://www.businessinsider.com/google-vs-amazon-in-cloud-is-likea-microsoft-phone-tech-exec-says-2016-8. It may be more frequent by now. use models (similar to cloud and vendor servicing models). In several of the companies in our study, funding is shifting to discrete purchases by business units, on an as-needed basis. Kaiser Permanente allows clinical and administrative departments to purchase technology services on its Generation 2 platform directly from the IT organization. Departments are billed monthly and can acquire or discard services depending on their needs and budgets.

Most established companies have been building, enhancing and leveraging their operational backbones for many years, so most participants in our research were experienced with the management practices in the left-hand column of Table 1. Practices in the right-hand column were newer, however. In general, the business and IT leaders we interviewed were just starting to recognize the need for - and then to adopt - these new practices.

\section{The Impact of Digital Transformation on the IT Unit}

As companies build new technology-enabled business capabilities, they introduce fundamental business changes. At most of the companies we studied, these changes had first-and most profoundly - affected the IT unit.

Kaiser Permanente transformed its IT organization by adopting a service-centric operating model. It now designs standard assemblies for IT services chosen by its business users. As part of Schindler's IT transformation, the company created Schindler Digital Business AG, which comprises 
teams focused on the operational backbone and teams specifically charged with digital innovation by building and maintaining digital services.

\section{"We have put them together as a new organization, fully focusing on this digital innovation part of the company. We need to have these people understanding that this is [their primary role], so when waking up in the morning they should think about digital business and not something else. That was super important: having this clear commitment." Michael Nilles, Chief Digital Officer, Schindler Group}

To enable new requirements for integration across vertical business units, some IT units are serving as integrators. At Schneider Electric, for example, the CIO deployed two architects just to facilitate changes involving multiple parts of the company so that the company could implement its digitized solutions strategy:

"I needed to work more as an orchestrator. The business leaders need to design their operating models, but we need some central thinking about how the design of all those businesses would impact Schneider on the whole and how we could purposefully create commonalities across the business to gain more scale." Hervé Coureil, CIO, Schneider Electric

As companies create integrated customer experiences and digitized solutions, many are reorganizing their IT units around services. Kaiser Permanente's Chief Technology Officer described the IT services management model as a great shiftfrom allocating funds to a few high-value projects to funding many small transactions:

"It [the IT services management model] reduces the barrier to entry, so the risk of failure-of it not being successful-is greatly minimized, and the cost to enter is also much lower. You can scale it very, very quickly for huge success. By doing that, we enable a lot more creativity and innovation, and we enable medium-sized projects to go ahead ... In the past you'd have to consult with everybody because if it didn't work, then your department just blew $\$ 50,000$, and someone else's pet project didn't get funded." Mike Sutten, Senior Vice President and Chief Technology Officer, Kaiser Permanente

Although the IT unit was usually the first part of a company to transform, participants in our research also anticipated that changes in the IT unit would eventually be reflected throughout the entire company. At Kaiser Permanente, for example, new digital services enabled more rapid innovations in delivering healthcare. Initially, the company incrementally introduced these changes, but redesign of the larger organization was expected to facilitate more dramatic - and important - changes to healthcare delivery over time. We anticipate that many of the changes our interviewees described will cascade across the entire enterprise. At some companies, that transformation is already underway.

\section{Recommendations for Digital Transformation at Big Old Companies}

SMACIT and other digital technologies have created a moment of truth for big old companies: they bring new customer expectations, younger, more nimble competitors and revolutionary managerial approaches. Since past success does not ensure future success, older companies will need to transform to take advantage of digital era opportunities.

Figure 1 summarizes our research findings on the digital transformation journeys big old companies will have to undertake. They must choose either a customer engagement or digitized solutions strategy, and this choice will shape priorities for building two essential technology-enabled assets: an operational backbone and a digital services platform. The operational backbone will ensure efficiencies of scale for critical transactional and decision-making capabilities. The digital services platform will ensure rapid innovation of critical digital offerings for customers. These two assets allow a company to execute its chosen digital strategy and, ultimately, to deliver both customer engagement and digitized solutions.

It is not easy for big old companies to let go of legacy systems, processes and cultures. To transform themselves to digital businesses, they must embark on a protracted journey. From our research, we 


\section{Figure 1: Elements of Digital Transformation at a Big Old Company}

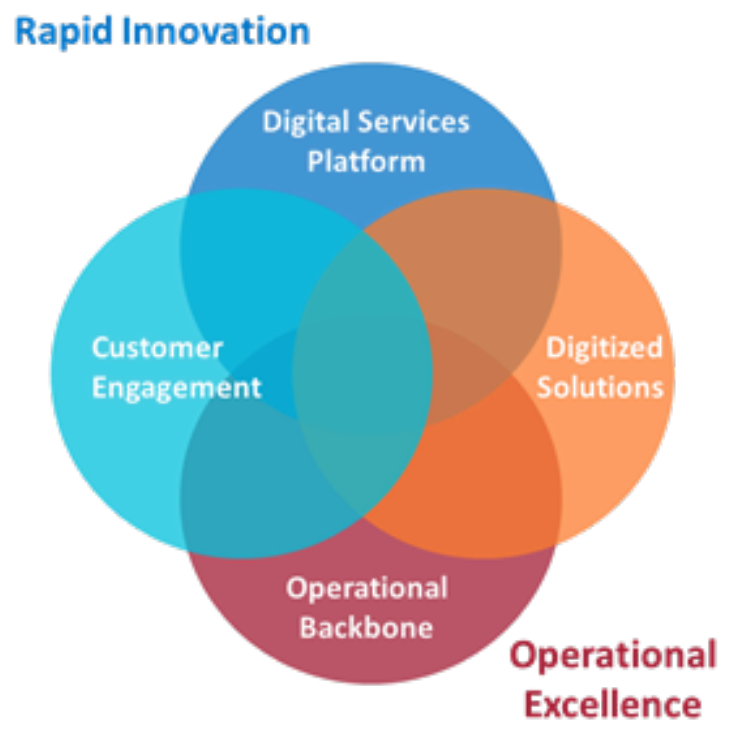

provide five recommendations for mapping a successful journey.

\section{Define a Digital Strategy}

By articulating a digital strategy (whether customer engagement or digitized solutions) a company's leaders can focus employees on clear objectives. With clear direction, a company can start building integrated, difficult-to-replicate capabilities to deliver on that strategy.

\section{Act Now to Invest in an Operational Backbone}

Today, investing in an operational backbone is a necessary prerequisite for success in the digital economy. Without such a backbone, a company will lack the foundational capabilities that are needed to enable its digital services platform to provide transaction transparency (e.g., the supply chain) and access to customer data, and to support standardized business processes (e.g., customer account opening, secure access, orders, payments). Just reaching agreement on which operational capabilities are most critical is an extraordinary leadership challenge. To get started in a meaningful way, senior managers should focus on building just one capability critical to the company's digital strategy, such as a well-designed customer database or a supply chain management system. A company without an operational backbone should seek help from cloud providers, vendors, business process outsourcersanyone who can accelerate the delivery of reusable, efficient and reliable operational capabilities.

\section{Architect a Digital Services Platform}

IT leaders can begin to define the architecture for a digital services platform by focusing on a small set of digital innovations they believe will be critical to business success. Once a company has established the data requirements for a small set of critical business components and has set up APIs for accessing the needed data, it can then build (or technology partners can help it build) the infrastructure needed to protect, connect, analyze and support innovative digital services.

\section{Design the Digital Services Platform with Partners in Mind}

Our study suggests that effective leaders recognize that customers, suppliers and other stakeholders will want to develop innovative business services or front-end apps that also become integrated capabilities (or common business services). The digital services platform should therefore be designed with those extensions in mind.

\section{Adopt a Services Culture}

Business and IT teams will jointly define, design, deliver, price, prioritize, implement, enhance and discard new business services. Companies 
are beginning to structure themselves around the services they provide. They are empowering service owners to deliver the innovations and efficiency that customers and employees expect. This transition is difficult, so it is prudent for the IT organization to start learning how to manage services-i.e., how to define and deliver IT services to business and IT partners. Organizations that have adopted the ITIL framework (a set of practices for IT service management that focuses on aligning IT services with the needs of business) have long embraced this approach to IT management. Over time, we believe, designing around business services will become the way most companies do business.

\section{Concluding Comments}

In an old-school divide-and-conquer approach, managers focused on optimizing the performance of their business unit or function. However, a divide-and-conquer mindset is not well suited to digital transformation. The most exciting SMACIT opportunities integrate products and services across functional, organizational and geographic boundaries. To succeed digitally, big old companies need to embrace new organizational structures and processes that empower their people to collaboratively experiment with technologies and deliver integrated products and services to their customers.

Companies that fail to adopt new technologies and fail to heed the need for digital transformation are likely to be left trailing behind in the dust. 


\section{Appendix: Research Methodology}

We solicited participants for our study by approaching CIOs in the 85 companies that sponsor the MIT Sloan Center for Information Systems Research (CISR), as well as CIOs in another four companies that we knew were becoming more digital. Boston Consulting Group also invited CIOs from companies that its consultants knew were in the midst of digital transformations.

We asked prospective study participants if they would like to participate in research on how companies were redesigning for the digital economy. While many responded that they were too early in their transformation journeys to participate in the study, and a few were concerned about the confidentiality of their digital initiatives, 25 companies agreed to participate. As shown in the table below, the companies came from a variety of industries. Most were big companies (thousands of employees) and old (only one was less than 25 years old). ${ }^{21}$

Between June 2014 and October 2016, we interviewed three senior executives at each of the

21 We have used broad ranges in the table to protect company confidentiality. Most companies in our sample were old. The mean and median ages were 104 years and 107 years, respectively. Only one company was founded after 1990 . The youngest was 18 years old; the oldest was 184 years old. Most of them were big companies, with mean and median number of employees of 82,297 and 27,900 respectively. Only four had less than 10,000 employees. The smallest had over 7,500 employees, and the largest had over 344,000.

\begin{tabular}{|c|c|c|c|}
\hline Company & Industry & Number of Employees & Year Founded \\
\hline 1 & Heavy Manufacturing & $50,000-99,999$ & Before 1900 \\
\hline 2 & Heavy Manufacturing & $>300,000$ & Before 1900 \\
\hline 3 & Heavy Manufacturing & $50,000-99,999$ & Before 1900 \\
\hline 4 & Heavy Manufacturing & $10,000-49,999$ & Before 1900 \\
\hline 5 & Heavy Manufacturing & $10,000-49,999$ & $1950-1999$ \\
\hline 6 & Other Manufacturing & $>300,000$ & $1900-1949$ \\
\hline 7 & Other Manufacturing & $100,000-300,000$ & Before 1900 \\
\hline 8 & Other Manufacturing & $100,000-300,000$ & Before 1900 \\
\hline 9 & Other Manufacturing & $100,000-300,000$ & Before 1900 \\
\hline 10 & Other Manufacturing & $10,000-49,999$ & $1900-1949$ \\
\hline 11 & Other Manufacturing & $10,000-49,999$ & $1900-1949$ \\
\hline 12 & Pharmaceuticals & $10,000-49,999$ & $1950-1999$ \\
\hline 13 & Civil Engineering & $50,000-99,999$ & $1950-1999$ \\
\hline 14 & Financial Services & $100,000-300,000$ & Before 1900 \\
\hline 15 & Financial Services & $10,000-49,999$ & $1900-1949$ \\
\hline 16 & Financial Services & $10,000-49,999$ & Before 1900 \\
\hline 17 & Life and Health Insurance & $<10,000$ & Before 1900 \\
\hline 18 & Software/IT Services & $100,000-300,000$ & $1950-1999$ \\
\hline 19 & Software/IT Services & $<10,000$ & $1950-1999$ \\
\hline 20 & Software/IT Services & $10,000-49,999$ & $1950-1999$ \\
\hline 21 & Information Services & $<10,000$ & $1950-1999$ \\
\hline 22 & Information Services & $<10,000$ & Before 1900 \\
\hline 23 & Healthcare & $100,000-300,000$ & $1900-1949$ \\
\hline 24 & Department Stores & $<10,000$ & $1900-1949$ \\
\hline 25 & Government & $10,000-49,999$ & $1900-1949$ \\
\hline
\end{tabular}


25 participating companies - at least one from the IT organization and at least one from a business function. The interviews were semi-structured and conducted by video or phone, with each taking about an hour. The interviews explored:

1. How the company assesses digital technology opportunities and how its industry is changing

2. The business strategies that the company's leaders were formulating to address digital opportunities

3. Organizational design changes (if any) that the company was implementing to execute its digital strategy.

We recorded and transcribed each interview. After coding the transcripts (manually or using the NVivo qualitative data analysis software), we prepared cases or shorter vignettes. For two companies, we conducted additional interviews and wrote full case studies. For the other companies, we summarized the interviews in vignettes written using a standard template (background, strategic context, business model changes, design changes).

We asked each company for permission to publish the case study or vignette. In addition to the two full case studies, nine companies approved their vignettes for publication. The following case studies and vignettes can be downloaded from CISR's website (http://cisr.mit.edu/publications-andtools/publication-search/five-ways-to-face-digitaldisruption/):

- Andersen, P. and Ross, J. W. Transforming the LEGO Group for the Digital Economy, MIT Sloan CISR Working Paper No. 407, March 2016.

- Beath, C. M., Moloney, K. G. and Ross, J. W. The Principal: Benefiting from a ServiceOriented Architecture, MIT Sloan CISR Working Paper No. 413, April 2016.

- Beath, C. M. and Ross, J. W. USAA: Defining a Digital Experience, MIT Sloan CISR Working Paper No. 410, April 2016.

- Betancourt, P., Mooney, J. and Ross, J. W. Digital Innovation at Toyota Motor North America: Revamping the Role of IT, MIT Sloan CISR Working Paper No. 403, September 2015.
- Fonstad, N. O. and Ross, J. W. Ferrovial: Leveraging Internal and External Resources to Innovate Competitively, MIT Sloan CISR Working Paper No. 409, April 2016.

- Kagan, M. H., Sebastian, I. M. and Ross, J. W. Kaiser Permanente: Executing a Consumer Digital Strategy, MIT Sloan CISR Working Paper No. 408, March 2016.

- Scantlebury, S. and Ross, J. W. Schneider Electric: Redesigning Schneider Electric's Operating Model, MIT Sloan CISR Working Paper No. 412, April 2016.

- Sebastian, I. M., and Ross, J. W. The Schindler Group: Driving Innovative Services and Integration with Schindler Digital Business AG, MIT Sloan CISR Working Paper No. 411, April 2016.

After preparing the cases and vignettes, we conducted a cross-case analysis. We recorded the qualitative codes about business model changes, design changes and various other themes in an Excel spreadsheet.

The following table details the status of the companies in our study, in terms of their digital strategy and whether they were building an operational backbone and/or a digital services platform. Companies fall into four groups: 1) Those that had built both an operational backbone and a digital services platform, 2) Those that have an operational backbone, but have not yet started to define a digital services platform, 3) Those that only have a digital services platform and 4) Those with neither (not included in the table). Differential shading in the table highlights differences according to each company's digital strategy (customer engagement, digitized solutions or no digital strategy articulated).

Most digital services platforms are still under construction or in the design phase. In our study, 12 of the 25 companies had created, or were in the process of designing, a digital services platform. In most cases (the 10 companies in Group 1), the operational backbone was developed before the digital services platform. The two digital strategy types were equally represented in Group 1 (five companies per strategy type), suggesting that both technology-enabled assets (an operational backbone and a digital services platform) are essential, regardless of whether the digital strategy focuses on digitized solutions or customer engagement. 


\section{Digital Strategies and Characteristics of the Technology-enabled Assets}

\begin{tabular}{|c|c|c|c|}
\hline Company & Strategy & Operational Backbone Characteristics & $\begin{array}{l}\text { Digital Services Platform } \\
\text { Characteristics }\end{array}$ \\
\hline & & Group 1 & \\
\hline 1 & DS & $\begin{array}{l}\text { Global standardized operational processes } \\
\text { (packaged software) }\end{array}$ & $\begin{array}{l}\text { Proactive and predictive monitoring with } \\
\text { sensor data }\end{array}$ \\
\hline 3 & DS & $\begin{array}{l}\text { Global standardized operational processes } \\
\text { (packaged software) }\end{array}$ & $\begin{array}{l}\text { Telematics and performance management with } \\
\text { sensor data }\end{array}$ \\
\hline 7 & DS & $\begin{array}{l}\text { Standardized shared customer relationship } \\
\text { management (cloud) }\end{array}$ & $\begin{array}{l}\text { Proactive and predictive monitoring with } \\
\text { sensor data }\end{array}$ \\
\hline 9 & DS & $\begin{array}{l}\text { Enterprise-wide standardized operational } \\
\text { processes - mostly cloud }\end{array}$ & $\begin{array}{l}\text { Aggregation and analysis of health, lifestyle, } \\
\text { clinical data from sensors, devices, EHRs }\end{array}$ \\
\hline 13 & DS & $\begin{array}{l}\text { Standardized shared CRM; business process } \\
\text { outsourcing (cloud) }\end{array}$ & Digital platform for innovation (in progress) \\
\hline 6 & $\mathrm{CE}$ & $\begin{array}{l}\text { Standardized operational processes; central } \\
\text { customer database (mostly cloud) }\end{array}$ & $\begin{array}{l}\text { Customer experience platform with telematics } \\
\text { and analytics }\end{array}$ \\
\hline 11 & $\mathrm{CE}$ & $\begin{array}{l}\text { Global standardized operational processes } \\
\text { (mostly packaged) }\end{array}$ & $\begin{array}{l}\text { Customer engagement platform focused on } \\
\text { real-time community (in progress) }\end{array}$ \\
\hline 15 & $\mathrm{CE}$ & Centralized customer database (home grown) & $\begin{array}{l}\text { Personalized, flexible customer experience } \\
\text { within a topic area (in progress) }\end{array}$ \\
\hline 16 & $\mathrm{CE}$ & $\begin{array}{l}\text { Centralized customer database and reusable } \\
\text { SOA components (home grown) }\end{array}$ & $\begin{array}{l}\text { Continually adjusted customer experience } \\
\text { with analytics and behavioral economics (in } \\
\text { progress) }\end{array}$ \\
\hline \multirow[t]{2}{*}{24} & $\mathrm{CE}$ & $\begin{array}{l}\text { Enterprise-wide EHR system (packaged } \\
\text { software) }\end{array}$ & $\begin{array}{l}\text { Same-day delivery of technology services to } \\
\text { clinical and operational departments }\end{array}$ \\
\hline & & Group 2 & \\
\hline 20 & DS & $\begin{array}{l}\text { Standardized key business processes and } \\
\text { organizational management system (home } \\
\text { grown) }\end{array}$ & N/A \\
\hline 26 & $\mathrm{CE}$ & $\begin{array}{l}\text { Enterprise-wide standardized operational } \\
\text { processes (home grown) }\end{array}$ & N/A \\
\hline 5 & N/A & $\begin{array}{l}\text { Global standardized operational processes } \\
\text { (packaged software) }\end{array}$ & N/A \\
\hline 10 & N/A & $\begin{array}{l}\text { Global standardized operational processes } \\
\text { (packaged software) }\end{array}$ & N/A \\
\hline \multirow[t]{2}{*}{12} & N/A & $\begin{array}{l}\text { Global standardized operational processes } \\
\text { (home grown) }\end{array}$ & N/A \\
\hline & & Group 3 & \\
\hline 2 & DS & N/A & Performance management with sensor data \\
\hline 19 & DS & N/A & $\begin{array}{l}\text { Knowledge, data, real-time community services } \\
\text { with analytics, facilitation of interactions }\end{array}$ \\
\hline
\end{tabular}

$\mathrm{DS}=$ digitized solutions strategy

$\mathrm{CE}=$ customer engagement strategy

N/A indicates that the company did not articulate a digital strategy during our interviews

Group 4, comprising eight companies $(4,8,14,17,18,21,22$ and 25), had neither an operational backbone nor a digital services platform.

This group is not included in the table. 
The five companies in Group 2 had built their operational backbone but had not yet defined a digital services platform, although we believe they were close to doing so. Three of these companies were likely held back by difficulties they were experiencing in choosing a digital strategy. In the other two, opportunities arising from new digital technologies were only beginning to come into focus in their industries; customer expectations had not yet begun to change, so pressure to change was low.

The two companies in Group 3, both with digitized solutions strategies, were each building a digital services platform but had not developed a strong operational backbone. One of these companies, in the software/IT services field, and comparatively young and small in terms of our sample, can be classified as "born digital." Borndigital companies invariably build digital services platforms before they build operational backbones because they don't need to manage the scale of a large company. The other company, a manufacturing business, was developing new, innovative solutions that focused on collecting, analyzing and providing insights about equipment. It had decided to move more aggressively on building a digital services platform, which is key to its new business model, than on building an operational backbone. In a way, this company was taking a start-up approach to its new digital solutions.

Seven of the eight companies in Group 4 with neither an operational backbone nor a digital services platform had selected a digital strategy but were struggling to execute on it and to start their digital transformation. Leaders in Group 4 were only beginning to articulate the characteristics of the two technology-enabled assets they would need. Most of these businesses were constrained by their silo structures both in business operations and IT management. 


\section{About the Authors}

\section{Ina M. Sebastian}

Ina M. Sebastian (isebasti@mit.edu) is a research scientist at the MIT Sloan School's Center for Information Systems Research (CISR), where she studies how large enterprises transform for success in the digital economy. Her current research areas are digital strategies and organizational redesign, digital workplace and talent management, and collaboration across organizational boundaries in ecosystems.

\section{Jeanne W. Ross}

Jeanne Ross (jross@mit.edu) is a principal research scientist at the MIT Sloan School's Center for Information Systems Research (CISR), where she lectures, conducts research and directs executive education courses on IT management practices. She studies digital transformations of large enterprises and the implications of technologies like cloud, mobile, data analytics and artificial intelligence.

\section{Cynthia Beath}

Cynthia Beath (cbeath@mail.utexas.edu) is Professor Emerita at the McCombs School of Business, University of Texas at Austin. She earned her M.B.A and Ph.D. degrees from UCLA. Before embarking on her academic career, she worked in private industry in several information systems development and consulting positions. Her research, which focuses on the joint management of information technology assets by IT, its vendors and its clients, has been published in leading information systems research journals. Her work has been supported by grants from the National Science Foundation, SIM International, IBM and others.

\section{Martin Mocker}

Martin Mocker (martin.mocker@reutlingenuniversity.de) is a professor of information systems at ESB Business School, Reutlingen University, Germany. He is also a research affiliate at the MIT Sloan School's Center for Information Systems Research (CISR). His research on managing business complexity, business architecture and digitization has been published, for example, in Harvard Business Review, Sloan Management Review, MIS Quarterly and European Journal of Information Systems.

\section{Kate G. Moloney}

Kate Moloney is a research specialist at the MIT Sloan School's Center for Information Systems Research (CISR). She researches how large companies leverage new technologies to create business value. Her current research focuses on artificial intelligence and blockchain technologies. She is particularly interested in the emergent enterprise and social challenges that these technologies present.

\section{Nils O. Fonstad}

Nils Fonstad (nilsfonstad@mit.edu) is a research scientist at the MIT Sloan School's Center for Information Systems Research (CISR) and is currently researching competitive digital innovation. Drawing on both in-depth qualitative data and survey data, he studies what investments and innovation practices distinguish the most competitive firms. $\mathrm{He}$ has also studied how organizations define, access and foster new skills and leaders for operating and innovating digitally. In 2010, he co-founded with CIONET the annual European CIO of the Year Awards to raise awareness of the expanding strategic roles of digital leaders. Nils earned his Ph.D. degree from MIT Sloan School of Management. 